\title{
SOME REACTIONS OCCURRING BETWEEN KSCN AND MOLTEN $\mathrm{NaNO}_{3}-\mathrm{KNO}_{3}$
}

\author{
M. E. MARTINS, A. J. CALANDRA and A. J. ARVIA \\ Instituto de Investigaciones Fisicoquímicas Teóricas y Aplicadas, División Electroquímica, Facultad de \\ Ciencias Exactas, Universidad Nacional de La Plata, La Plata, Argentina
}

(Received 20 April 1973)

\begin{abstract}
When KSCN is added to molten $\mathrm{NaNO}_{3}-\mathrm{KNO}_{3}$ eutectic within the range of $230-316^{\circ} \mathrm{C}$, a complex and a relatively violent chemical reaction takes place until a KSCN concentration of ca. $1 \mathrm{~m}$ equiv KSCN/100 g eutectic has been added; further addition produces only a small residual chemical reaction. The reaction yields $\mathrm{NO}_{2}^{-}, \mathrm{SO}_{4}^{2-}$ ions and basic ionic species in the melt and $\mathrm{NO}_{2}, \mathrm{CO}_{2},(\mathrm{CN})_{2}$, $\mathrm{N}_{2} \mathrm{O}$ and minor quantities of other gaseous products. The reaction is interpreted in terms of ionic equilibria involving $\mathrm{NO}_{3}^{-}, \mathrm{NO}_{2}^{-}, \mathrm{SCN}^{-}, \mathrm{O}_{2}^{2-}, \mathrm{O}^{2-}, \mathrm{O}_{2}^{-}$and $\mathrm{O}^{2-}$ ions and $\mathrm{O}_{2}$ as principal reacting species.
\end{abstract}

\section{INTRODUCTION}

DURING the course of an investigation of the electrochemistry of $\mathrm{SCN}^{-}$ion dissolved in different molten salts, a chemical reaction was observed when small amounts of $\mathrm{KSCN}$ were added to molten $\mathrm{NaNO}_{3}$ $\mathrm{KNO}_{3}$ (1:1 molar ratio). Under these circumstances the electrolysis of the molten solution gave an anodic carrent/potential curve on platinum electrodes which exhibited a neat current related to the $\mathrm{NO}_{2}^{-}$ion electrochemical oxidation[1] largely exceeding that corresponding to the amount of $\mathrm{NO}_{2}^{-}$ion present as impurity in the melt. The half-wave potential related to the anodic oxidation of $\mathrm{NO}_{2}^{-}$ion is less anodic than the potential where the $\mathrm{SCN}^{-}$ion is electrochemically oxidized $[2,3]$.

These findings however were not reported by different authors who had previously investigated ternary systems formed by nitrates and thiocyanates of lithium, sodium and potassium[4-9] although one of them observed some decomposition reaction which was not fully understood $[10]$.

It is therefore interesting to clarify the chemistry of these systems and to identify any possible reactions.

\section{EXPERIMENTAL}

Chemicals of analar quality previously purified as indicated elsewhere were employed[2,3]. The $\mathrm{NaNO}_{3}-\mathrm{KNO}_{3}$ eutectic (1:1 molar ratio) was dried firstly at ca. $120^{\circ} \mathrm{C}$ for 3 days and later by heating under vacuum, at about $10^{\circ} \mathrm{C}$ above the melting point, for $3 \mathrm{hr}$. Solid KSCN was first vacuum dried at room temperature for $12 \mathrm{hr}$. Later the temperature was regularly increased, the salt melting under vacuum. Finally it was cooled down to obtain small bead shaped samples to be used as electrolyte.

Potassium thiocyanate solutions were usually made either under vacuum or under nitrogen atmosphere; a few solutions were prepared under open air.
Potentiostatic current/potential curves were recorded using a conventional electrolysis cell with a platinum rotating disk working electrode of $0.071 \mathrm{~cm}^{2}$ area; a platinum counterelectrode and a $\mathrm{Ag} / 0.1 \mathrm{M} \mathrm{AgNO}_{3}\left(\mathrm{NaNO}_{3}-\right.$ $\mathrm{KNO}_{3}$ melt) electrode was employed as a reference. Further details about the cell and the experimental setup are given in the literature $[1,2]$. Runs were made at 230, 250, 280 and $316^{\circ} \mathrm{C}$, covering a $\mathrm{KSCN}$ concentration range from 0.01 to $1.69 \mathrm{~m}$-equiv $/ 100 \mathrm{~g}$ eutectic, with the working electrode under rotation at different speeds.

A specially designed glass reactor provided facilities for both mixing the reactants (KSCN and the eutectic) and separating the gaseous products from the chemical reaction. The reactor was operated in conjunction with a conventional vacuum line.

Both reactants and products (gases and dissolved products) were analysed by the usual techniques. As nitrate melts may undergo some thermal decomposition even at a few degrees above the melting point, blank experiments were systematically run to avoid any possible contribution of products of this kind.

Solutions of KSCN in molten $\mathrm{NaNO}_{2}-\mathrm{KNO}_{2}$ were also made and current/potential curves were run as described. The $\mathrm{NaNO}_{2}-\mathrm{KNO}_{2}$ melt was purified as previously described $[11]$.

\section{RESULTS}

\section{Products of the chemical reaction}

When a small portion of KSCN $(0.05$ m-equiv/ $100 \mathrm{~g}$ solvent) is added to the carefully dehydrated nitrate melt, a rather violent reaction is observed during a short time. When a second portion of $\mathrm{KSCN}$ is added to the homogenized melt, the chemical reaction is practically no longer observed. These experiments were conducted by changing the $\mathrm{KSCN}$ concentration between 0.05 and $24 \mathrm{~m}$-equiv/ $100 \mathrm{~g}$ solvent.

The reaction products found in the melt after cooling and dissolving in water, are $\mathrm{NO}_{2}^{-}$and $\mathrm{SO}_{4}^{2-}$ ions. The 
alkaline reaction of an aqueous solution of the cooled salt mixture showed the formation of basic species, probably oxide ions, during the reaction. The remaining $\mathrm{SCN}^{-}$ion, the $\mathrm{SO}_{4}^{2-}$ content as well as the alkaline content of the melt were potentiometrically titrated with the usual procedures. The $\mathrm{NO}_{2}^{-}$ion content was determined spectrophotometrically with a solution of sulphanilic acid and $\alpha$-naphtylamine dissolved in glacial acetic acid.

The content of basic species increases with the amount of KSCN dissolved, approaching a limiting value for a relatively high $\mathrm{KSCN}$ concentration, as described further on for the $\mathrm{NO}_{2}^{-}$ion. Blank experiments with the solvent alone gave practically neutral aqueous solutions.

The gaseous reaction products were separated and analysed by i.r. techniques. For one experiment conducted under vacuum where the final KSCN concentration was $1.78 \mathrm{~m}$-equiv $/ 100 \mathrm{~g}$ solvent, a slightly browncoloured mixture of gases was formed. The pressure increase in the system corresponded to about 30 per cent of the total KSCN added.

The following compounds were identified in the spectrum in a decreasing quantitative proportion: $\mathrm{NO}_{2}\left(1618 \mathrm{~cm}^{-1}\right), \mathrm{CO}_{2}\left(2349 \mathrm{~cm}^{-1}\right),(\mathrm{CN})_{2}(2149$ and $\left.738 \mathrm{~cm}^{-1}\right), \mathrm{N}_{2} \mathrm{O}\left(1286\right.$ and $\left.2224 \mathrm{~cm}^{-1}\right), \mathrm{N}_{2} \mathrm{O}_{4}(1262$ $\left.\mathrm{cm}^{-1}\right)$, NO $\left(1876 \mathrm{~cm}^{-1}\right)$ and $\operatorname{SCO}\left(2349 \mathrm{~cm}^{-1}\right)$.

After the reaction the eutectic acquired a yellowish tinge. In addition, some small KSCN crystals which remained adhered to the inlet glass tubing without coming into contact with the nitrate melt, underwent a further reaction with the gaseous products already formed, yielding $(\mathrm{SCN})_{x}$. The temperature of the reactor in this region was about $100^{\circ} \mathrm{C}$.

Experiments were also made using either a mixture of $\mathrm{NaNO}_{3}-\mathrm{KNO}_{3}$ with $\mathrm{KNO}_{2}$ changing from 2.99 to $7.96 \mathrm{~m}$-equiv $/ 100 \mathrm{~g}$ solvent or a $\mathrm{NaNO}_{2}-\mathrm{KNO}_{2}$ eutectic. When small portions of $\mathrm{KSCN}$ were added to the nitrate-nitrite melt a slow increase of $\mathrm{NO}_{2}^{-}$ion was observed during a period of several days on standing the melt in contact with air. These experiments indicate that gaseous oxygen plays its part in the chemical reactions. A probably different reaction occurs with the nitrite eutectic which proceeds very much more slowly.

\section{Electrochemical measurements}

The $\mathrm{KNO}_{3}-\mathrm{NaNO}_{3}$ melt, containing different concentrations of $\mathrm{KSCN}$, was anodically electrolysed under nitrogen, under potentiostatic conditions, with a platinum disk anode, at rotation speeds from 216 to $1510 \mathrm{rev} / \mathrm{min}$.

The current/potential curves in the potential range from 0.7 to $0.95 \mathrm{~V}$, exhibit an anodic current plateau with a $E_{1 / 2}=0.50 \mathrm{~V}$. (Fig. 1), which corresponds to that of the anodic oxidation of $\mathrm{NO}_{2}^{-}$ion dissolved in the nitrate melt [1]. This was confirmed by running current/ potential curves with melts where known amounts of $\mathrm{NaNO}_{2}$ were added. The limiting currents in both



Fig. 1. Potentiostatic stationary current/potential curves recorded at different rotation speeds, $250^{\circ} \mathrm{C}, \mathrm{NO}_{2}^{-}$ion concentration found : $2.2 \times 10^{-3} \mathrm{M}$.

cases increased linearly with the square root of the rotation speed of the working electrode as corresponds to a convective-diffusion rate controlled process[1]. This allows one to employ the linear limiting current/ nitrite concentration relationship to evaluate the amount of $\mathrm{NO}_{2}^{-}$ion formed on the $\mathrm{KSCN} /$ nitrate melt, on the assumption that in the dilute region neither the viscosity of the melt nor the diffusivity of $\mathrm{NO}_{2}^{-}$ion are appreciably altered by the presence of the solute. The procedure consisted in comparing, at constant rotation speed and temperature, the anodic limiting currents obtained with the $\mathrm{KSCN} /$ nitrate melt with that obtained for the $\mathrm{NO}_{2}^{-} /$nitrate melt. Both $\mathrm{NO}_{2}^{-}$ion concentrations, evaluated either chemically or electrochemically, were in good agreement.

\section{Correlation of results}

The amount of $\mathrm{NO}_{2}^{-}$ion formed (or the quantity of $\mathrm{SCN}^{-}$ion remaining in the melt) changes with the ratio $[\mathrm{KSCN}] /[$ nitrate melt $]$, as shown in Fig. 2. Under vacuum and without $\mathrm{NO}_{2}^{-}$ion addition, the chemical reaction between $\mathrm{KSCN}$ and the nitrate melt yielding $\mathrm{NO}_{2}^{-}$ion occurs in the range of $\mathrm{KSCN}$ concentration from 0 to $1.5 \mathrm{~m}$-equiv $/ 100 \mathrm{~g}$. This range is reduced when $\mathrm{KNO}_{2}$ is added to the melt. Beyond $1.5 \mathrm{~m}$-equiv $/ 100 \mathrm{~g}$ a further addition of $\mathrm{KSCN}$ produces no appreciable increase in the $\mathrm{NO}_{2}^{-}$ion concentration. The initial slope of the curve shown in Fig. 2 yields an average of 2 ion grams of $\mathrm{NO}_{2}^{-}$ion formed per mole of KSCN added to the melt.

These results can be expressed in a different way by plotting the amount of KSCN added vs the amount of KSCN actually present in the melt. In the low concentration region (Fig. 3) the points lie below the ideal straight line having a slope equal to one, corresponding 


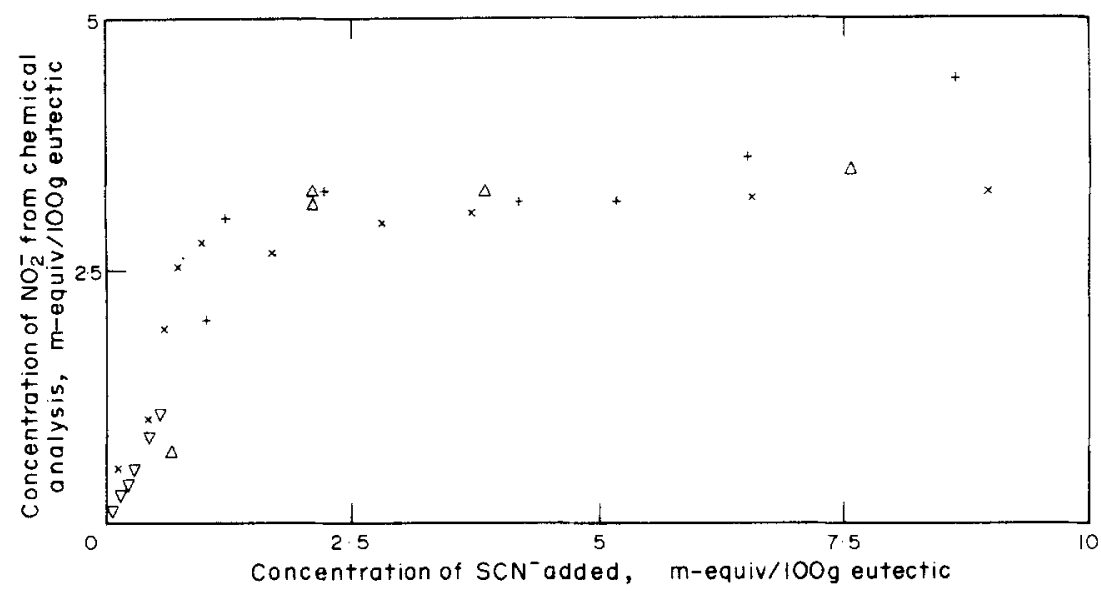

Fig. 2. Relationship between the amount of $\mathrm{KSCN}$ added to the melt and the amount of $\mathrm{NO}_{2}^{-}$ion determined by chemical analysis after the reaction. Data obtained at $250^{\circ} \mathrm{C}$.

to the absence of any decomposition of $\mathrm{KSCN}$. Otherwise, the results obtained at high KSCN concentration (Fig. 3) approaches the ideal relationship. The true line, which does not pass through the origin, lies below the ideal one.

The results are nearly the same over the whole temperature range investigated.

\section{DISCUSSION}

Results clearly show that the reaction between KSCN and the nitrate melt occurring at low $\mathrm{KSCN}$ concentration leads to a limiting concentration of reaction products. The total reaction involves a change in the ionic composition of the system due to the addition of the KSCN. The effect of adding $\mathrm{KSCN}$ is as if ionic

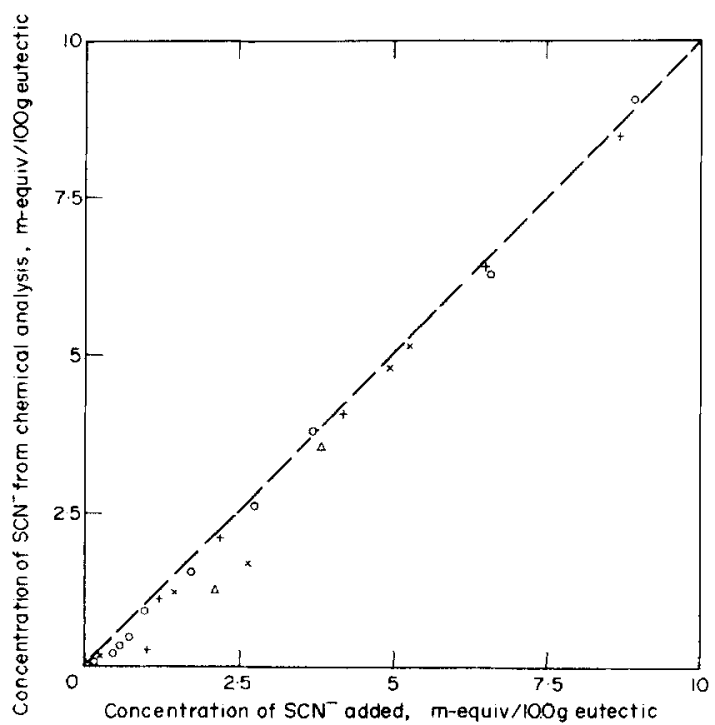

Fig. 3. Relationship between the amount of KSCN added to the melt and the amount of $\mathrm{SCN}^{-}$ion determined by chemical analysis after the reaction. Data obtained at $250^{\circ} \mathrm{C}$. equilibria involving highly oxidant species of the solvent are shifted giving an increase in the concentration of basic species and $\mathrm{NO}_{2}^{-}$ions. It is also clear that the possible equilibria must be linked to the presence of oxygen and $\mathrm{NO}_{2}^{-}$ion in the melt. The formation of the latter can be understood, taking into account that thiocyanate melts are more basic than molten alkali nitrates[12]. A direct chemical reaction between KSCN and the nitrate melt appears rather unlikely, otherwise one would expect a simple stoichiometry to hold between the $\mathrm{SCN}^{-}$and $\mathrm{NO}_{2}^{-}$species over the whole concentration range.

However, to interpret the reaction in terms of ionic processes two main possibilities exist. One of them is based on the assumption the main dissociation reaction of the $\mathrm{NO}_{3}^{-}$ion involves the nitronium and oxide ions [13], according to :

$$
\mathrm{NO}_{3}^{-}=\mathrm{NO}_{2}^{+}+\mathrm{O}^{2-} \text {, }
$$

the oxidizing power of nitrate melts being related to the nitronium ion. The second alternative, supposes that ionic species such as $\mathrm{O}_{2}^{-}, \mathrm{O}_{2}^{2-}$ and $\mathrm{O}^{2-}$ are mainly responsible for the oxidizing properties of molten nitrates, as recently suggested $[14,15]$. As the latter gives a more plausible explanation of the electrochemical behaviour of molten nitrates[16], it will be considered first in discussing the present results. The concentrations of these species at $500^{\circ} \mathrm{K}$ decrease in the order $\mathrm{O}_{2}^{-}>\mathrm{O}_{2}^{2-}>\mathrm{O}^{2-}[15]$, which is also the decreasing order of their oxidizing power. They participate in the following equilibria:

$$
\begin{aligned}
\mathrm{O}^{2-}+\mathrm{NO}_{3}^{-} & =\mathrm{NO}_{2}^{-}+\mathrm{O}_{2}^{2-} \\
\mathrm{O}_{2}^{2-}+2 \mathrm{NO}_{3}^{-} & =2 \mathrm{NO}_{2}^{-}+2 \mathrm{O}_{2}^{-} \\
2 \mathrm{O}_{2}^{-} & =\mathrm{O}_{2}^{2-}+\mathrm{O}_{2} .
\end{aligned}
$$

By addition of equilibria (2) and (3)

$$
\mathrm{O}^{2-}+3 \mathrm{NO}_{3}^{-}=3 \mathrm{NO}_{2}^{-}+2 \mathrm{O}_{2}^{-} \text {. }
$$


In the presence of $\mathrm{SCN}^{-}$ions the following oxidation will occur:

$$
2 \mathrm{SCN}^{-}=(\mathrm{SCN})_{2}+2 e
$$

where $(\mathrm{SCN})_{2}$ is an unstable product at the temperature of the melt. The occurrence of reaction (6) must be counterbalanced by a reduction reaction.

Among the passible reduction processes in the pure nitrate melt the following are relevant:

$$
\begin{aligned}
\mathrm{O}_{2}^{-}+e & =\mathrm{O}_{2}^{2-} \\
\mathrm{O}_{2}^{2-}+2 e & =2 \mathrm{O}^{2-} \\
\mathrm{NO}_{3}^{-}+e & =\mathrm{NO}_{2}+\mathrm{O}^{2-} \\
2 \mathrm{NO}_{3}^{-}+8 e & =\mathrm{N}_{2} \mathrm{O}+50^{2-} \\
\mathrm{NO}_{3}^{-}+2 e & =\mathrm{NO}_{2}^{-}+\mathrm{O}^{2-} \\
\mathrm{NO}_{3}^{-}+3 e & =\mathrm{NO}+2 \mathrm{O}^{2-} \\
2 \mathrm{NO}_{3}^{-}+10 e & =\mathrm{N}_{2}+60^{2-} .
\end{aligned}
$$

At $327^{\circ} \mathrm{C}, \mathrm{pO}^{2-}$ and unit activity of the nitrogen containing species, reactions (9)-(13) are thermodynamically ordered as follows[17]: $E^{0}(11)<E^{0}(9)<$ $E^{0}(12)<E^{0}(10)<E^{0}(13)$, where $E^{0}(n)$ refers to the equilibrium potential of reaction $n$.

Therefore the occurrence of reaction (6) coupled with any of reactions (7)-(13) changes the ionic composition of the system leading to an energetically favourable equilibrium which besides compensating for the decomposition of $(\mathrm{SCN})_{2}$, leads to a macroscopically stable $\mathrm{KSCN} /$ molten nitrate system.

In principle the total reaction yields $\mathrm{O}^{2-}$ and $\mathrm{NO}_{2}^{-}$ ions and, through the participation of either reactions (9), (10) or (12), nitrogen oxides. The presence of NO, although as a minor component in the gaseous reaction products in the absence of oxygen, makes significant $\mathrm{O}_{2}$ formation rather unlikely. The formation of $\mathrm{O}^{2-}$ induces $\mathrm{NO}_{2}^{-}$formation through an equilibrium such as (5). This implies a change of $\mathrm{pO}^{2-}$ in the system buffering the decomposition of $\mathrm{SCN}^{-}$ion. Thus the system approaches the $\left[\mathrm{SCN}^{-}\right] /\left[\mathrm{NO}_{3}^{-}\right]$ratio corresponding to its apparent macroscopic stability. The presence of $\mathrm{O}_{2}$, through equilibrium (4), induces the decomposition of $\mathrm{SCN}^{-}$ion and yields $\mathrm{NO}_{2}^{-}$ion as one of the products.

If the preceding reaction pathway, involving reactions (6), (7), (8) and (5), is responsible for the $\mathrm{NO}_{2}^{-}$ion formation, the maximum yield would be 2 iongrams of $\mathrm{NO}_{2}^{-}$ion per mole of $\mathrm{KSCN}$ decomposed. If the main reactions were (6), (9) and (5), then the maximum $\mathrm{NO}_{2}^{-}$ion yield would be 3 iongrams of $\mathrm{NO}_{2}^{-}$ion per mole of KSCN decomposed. The experimental yield for $\left[\mathrm{SCN}^{-}\right] \rightarrow \mathrm{O}$ is between 2 and 3 , suggesting the probable participation of all the above mentioned processes in the total reaction.

The nitrogen oxides and $(\mathrm{SCN})_{2}$, products of the main chemical reaction, may react in different ways either in the liquid or in the gaseous phase. As already established, the following reaction occurs [8]:

$$
(\mathrm{SCN})_{2}=(\mathrm{CN})_{2}+\mathrm{S}
$$

and also to some extent:

$$
x(\mathrm{SCN})_{2}=(\mathrm{SCN})_{2 x},
$$

yielding orange-red parathiocyanogen. Sulphur, finally reacts in the nitrate melt yielding $\mathrm{SO}_{4}^{=}$ions, as proven in separate experiments.

Nitrogen dioxide dissolved in the melt is also able to oxidize $\mathrm{SCN}^{-}$ion according to:

$$
2 \mathrm{NO}_{2}+2 \mathrm{SCN}^{-}=(\mathrm{SCN})_{2}+2 \mathrm{NO}_{2}^{-},
$$

both products participating in the previously described reactions. Finally the presence of $\mathrm{NO}_{2}$ in the melt modifies the $\mathrm{O}_{2}^{2-}$ ion concentration, through the equilibrium [14]:

$$
\mathrm{O}_{2}^{2-}+2 \mathrm{NO}_{2}=2 \mathrm{NO}_{3}^{-}
$$

The oxidation of $(\mathrm{SCN})_{x}$ in the melt probably causes the formation of a small amount of SCO, although this oxidation process is far from proven.

The presence of NO among the gaseous reaction products is not surprising, although a process such as (12) seems to be ruled out, because the following equilibrium is established in the nitrate melt[19]:

$$
\mathrm{NO}_{2}^{-}+\mathrm{NO}_{2}=\mathrm{NO}_{3}^{-}+\mathrm{NO} .
$$

Therefore, the reactions discussed give a coherent explanation of the chemical behaviour of the ternary molten $\mathrm{KSCN}-\mathrm{NaNO}_{3}-\mathrm{KNO}_{3}$ mixtures. It is certainly a rather more complex system than was earlier supposed.

A second interpretation of the reaction occurring between KSCN and molten alkali nitrate can be attempted in terms of equilibrium (1), although the existence of $\mathrm{NO}_{2}^{+}$in the molten nitrates is still a matter of discussion[20]. In this case the electron transfer processes responsible for the decomposition of KSCN should be:

$$
2 \mathrm{SCN}^{-}=(\mathrm{SCN})_{2}+2 e
$$

and

$$
2 \mathrm{NO}_{2}^{+}+2 e=2 \mathrm{NO}_{2} \text {. }
$$

The $\mathrm{O}^{2-}$ ions left in excess provide the change of $\mathrm{pO}^{2-}$ to compensate the redox potential in the melt and buffer the $\mathrm{SCN}^{-}$ion decomposition. The following chemical reactions should provide an excess of $\mathrm{NO}_{2}^{-}$ ion over the amount of $\mathrm{SCN}^{-}$ion decomposed to explain the formation of the different reaction products. These processes are however not so straightforwardly represented as in the first interpretation based upon the existence of $\mathrm{O}_{2}^{-}, \mathrm{O}_{2}^{2-}$ and $\mathrm{O}^{2-}$ ions in the melt. An interpretation based on equilibrium (1) seems much less probable.

Acknowledgement - This work is part of the research program of INIFTA (Electrochemistry Division) sponsored by the Universidad de La Plata, the Consejo Nacional de Investigaciones Cientificas y Técnicas and the Comisión de Investigaciones Cientificas de la Provincia de Buenos Aires. 


\section{REFERENCES}

1. M. E. Martins, A. J. Calandra and A. J. Arvia, Electrochim. Acta 15, 111 (1970).

2. M. E. Martins, A. J. Calandra and A. J. Arvia, Electrochim. Acta 16, 2057 (1971).

3. M. E. Martins, A. J. Calandra and A. J. Arvia, Electrochim. Acta 17, 741 (1972).

4. R. Riccardi and P. Franzosini, Gazz. chim. Ital. 92, 386 (1962).

5. B. J. Brough and D. H. Kerridge, J. chem. Engng Data 11, 260 (1966).

6. G. Piantoni, M. Braghetti and P. Franzosini, Ricerca. scient. 38, 942 (1968); G. Piantoni, D. Leonesi, A. Cingolani and P. Franzosini, Ricerca scient. 38, 1042 (1968).

7. M. Braghetti, G. Piantoni and M. Gambugiati, Ann. Chim. 60, 420 (1970).

8. G. Berchiesi, A. Cingolani and D. Leonesi, Z. Naturf. 25, 1768 (1970).

9. N. M. Sokolov and O. I. Dmitrevskaya, Russ. J. inorg. Chem. 15, 1633 (1970).
10. P. Franzosini, Private communication.

11. A. J. Calandra and A. J. Arvia, Electrochim. Acta 11. 1173 (1966)

12. K. W. Fung and G. Mamantov, In Advances in Molten Salt Chemistry, In press.

13. F. R. Duke, J. chem. Educ. 39, 57 (1962); N. Gupta and B. R. Sundheim, J. electrochem. Soc. 112, 1789 (1965).

14. P. G. Zambonin and J. Jordan, J. Am. chem. Soc. 91 , 2225 (1969); P. G. Zambonin. J. electroanal. Chem. 24, 365 (1970).

15. J. Jordan, J. electroanal. Chem. 29, 127 (1971).

16. M. G. Sustersic, W. E. Triaca and A. J. Arvia, Electrochim. Acta. In press.

17. S. L. Marchiano and A. J. Arvia, Electrochim. Acta 17, 25 (1972).

18. G. Metzger, Rapport CEA-R2566, Centre d'Etudes Nucléaires de Saclay, 1964.

19. L. E. Topol, R. A. Osteryoung and J. H. Christie, J. phys. Chem. 70, 2857 (1966).

20. P. G. Zambonin, J. electroanal. Chem. 32, App. 1-4 (1971). 